\title{
A flint artefact (Accession No. DONMG 2016.7.1) from Lindholme, South Yorkshire
}

\author{
Alan Saville $^{1}$, Paul C. Buckland ${ }^{2}$ \\ 1. National Museum of Scotland, Edinburgh, Scotland, U.K. \\ 2. Independent Researcher. 20 Den Bank Close, Sheffield, S10 5PA, U. K. Email: paul.buckland@bugscep.com
}

Keywords: late glacial; Late Upper Palaeolithic; Yorkshire; flint; Last Glacial Maximum

\section{Introduction (by Paul C. Buckland)}

One of the last papers which Alan was working on when he died was a short note on a flint artefact from the surface of a gravel scrape at Lindholme in South Yorkshire. This was found during fieldwork by Robert Friend, a postgraduate student in Geography at the University of Edinburgh, working on the limits of the last glaciation in the Vale of York (Friend 2011). The results of this have been published elsewhere (Bateman et al. 2015; Friend et al. 2016), but the context of the artefact is ambivalent and Alan's appendix on the flint was judged too archaeological and site specific for inclusion in either paper. It is a find, however, worth placing on record as one of a number of scattered surface finds of Upper Palaeolithic affinity from the region (compare with Garton et al. 2016; Grassam \& Weston 2015; Harding et al. 2014).

\section{The Artefact}

The single flint artefact (Figure 1) retrieved at this location is a substantial, retouched flint blade: $79 \mathrm{~mm}$ long, $20 \mathrm{~mm}$ in maximum breadth, and $10 \mathrm{~mm}$ in maximum thickness, with a weight of $16 \mathrm{~g}$. The surface of the flint, which retains no cortex, is densely discoloured (corticated or patinated) to a pale yellow-brown, overlain in places by patches and spots of reddish-brown staining. There are no modern breaks or edge damage to reveal what colour the flint was prior to discolouration, and the likely source of the raw material is unknown.

The blade has been struck from a blade core as shown by the two parallel longitudinal dorsal scars and is semi-crested with two negative flake scars, on the right-hand side of the blade, which are not struck from the ridge of this blade, but originate from an earlier stage of working the core. The negative flake scar at the distal end of the right-hand side of the blade, which terminates in a hinge fracture (as does the scar below it), also predates the production of this blade. Both these hinged-out scars have terminated against an inconsistency in the flint which leaves a triangular shaped area standing slightly proud on this edge. ISSN: 2055-0472. URL: http://journals.ed.ac.uk/lithicstudies/ 

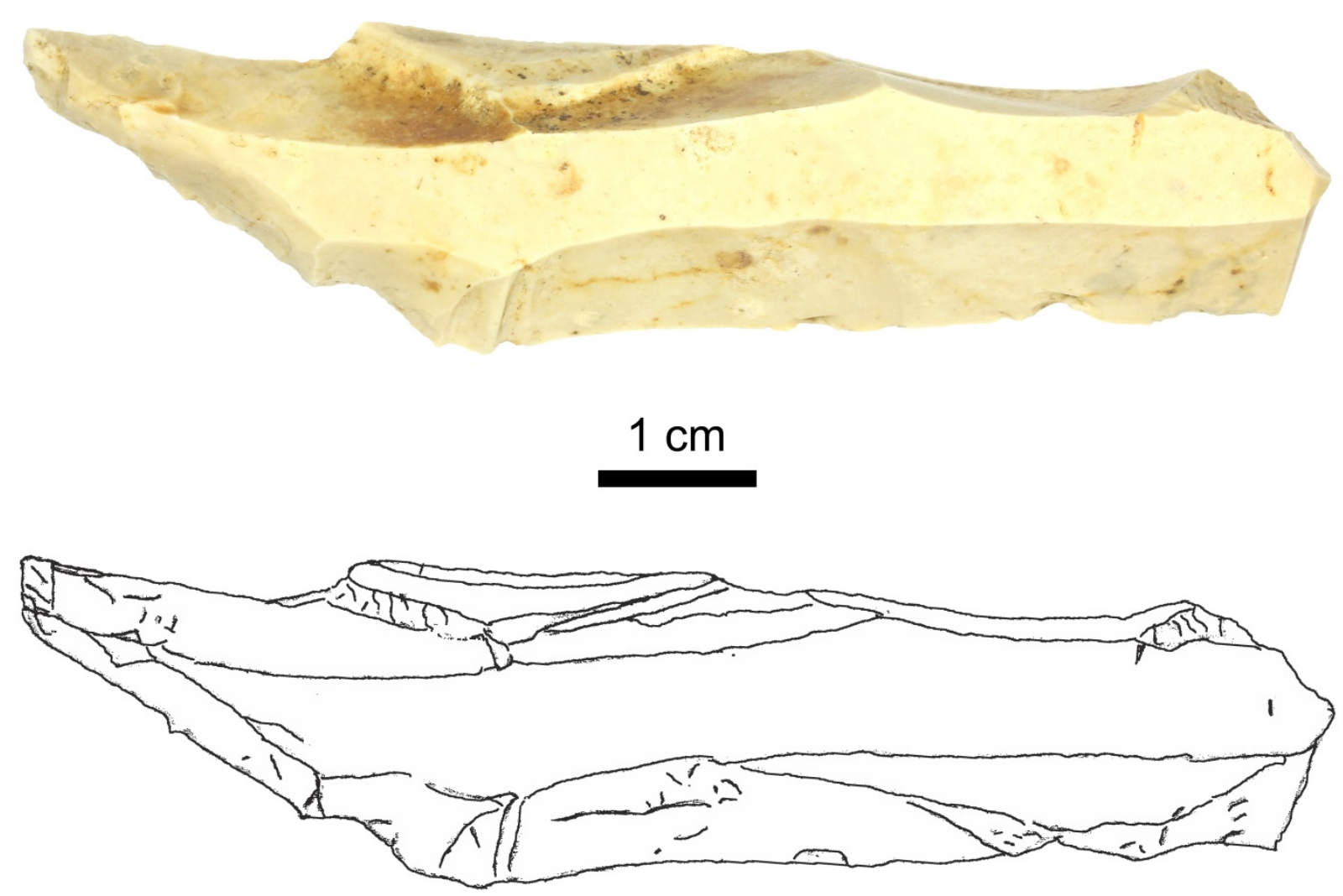

Figure 1. The artefact. (Photo by P.C. Buckland, drawing by J.M. Buckland.)

At the proximal end the striking platform is absent as a result of a bending fracture which has terminated in a slight hinge on its uppermost edge. There is slight retouch the righthand side of the base but it is difficult to evaluate. One retouch scar is on the actual break facet and may not be intentional. The other retouch scar is just before the break and is associated with a very small zone of edge-crushing at the dorsal-ventral interface. On the basal left-hand side of the blade a short stretch of nibbling retouch runs up to the break and may have been truncated by it. In short it appears the base of the blade was retouched, but if this was to produce a functional terminal the purpose remains obscure.

Apart from the basal trimming already mentioned, and a couple of nicks representing ancient damage, the modification of the left-hand edge of the blade is restricted to the distal end. Here steep, semi-blunting retouch has created an oblique edge leading to a robust point. There is no opposing retouch, but there are indications of edge wear at the top right-hand side, and there is clear rounding of the arrises of the retouch scars at the tip of the point. It is important to stress that the retouch post-dates the superficially burin-like scar on the righthand side, which relates to an earlier stage of core-working prior to the creation of this blade.

\section{Discussion}

Typological characterization of this artefact is somewhat hampered by uncertainty over the original form of the proximal end. It is just possible this was a composite tool with a functional proximal terminal. Otherwise, the significant feature is the oblique retouch at the distal end. Although this retouch is atypically unilateral, the form and macroscopic indications of use-wear suggest designation as a piercer, or perhaps more specifically a bec, i.e. a piercing tool with a relatively thick point. Whether or not it could be classed as an atypical Zinken is a moot point. What this artefact is definitely not is a projectile point (too thick or heavy) or a burin (no burin facet or edge). 
There are several aspects to this implement which help in an assessment of its likely age. Its deeply discoloured condition, its size and lack of cortex (struck from a large core or nodule), and its blade and blade-core character all point towards an Upper Palaeolithic-Early Mesolithic time frame. Are there any features about its typology which might give a closer chronological focus? Not definitively, but my subjective conclusion would be that a Magdalenian-type Later Upper Palaeolithic context is perhaps the most probable.

\section{Comments (by Paul C. Buckland)}

The stratigraphic sequence exposed in the pit at Lindholme consists of over two metres of laminar and ripple bedded sands with scattered small limestone erratics, over Triassic Sherwood Sandstone. The upper part of the section consists of a heavily cryoturbated diamicton ('till'). The erratic content of the diamicton indicates origins in a glacier moving down the western side of the Vale of York, from the Dales and over Stainmore (Friend et al. 2016). Bateman's OSL dates (Bateman 1995) show that the deposits are more recent than 18,000 BP. The artefact was picked up on the floor of the pit and unfortunately cannot satisfactorily be related directly to the deposits. Cryoturbation has rendered the upper part of the diamicton structureless and large dreikanters on the field surface indicate significant deflation, presumably during the episodes of blown sand deposition against the west facing scarps of the Isle of Axholme and Lincoln Edge to the east (Bateman 1995). Dating of the artefact therefore has to rely on its typology and its Late Upper Palaeolithic form suggests that it probably derives from a pocket of Late glacial sediments close to the modern ground surface, below any modern plough disturbance.

\section{References}

Bateman, M.D. 1995, Thermoluminescence dating of the British coversand deposits. Quaternary Science Reviews, 14(7-8): 791-798. doi:10.1016/0277-3791(95)00053-4

Bateman, M.D., Evans, D.J.A., Buckland, P.C., Connell, E.R., Friend, R.J., Hartmann, D., Moxon, H., Fairburn, W.A., Panagiotakopulu, E. \& Ashurst, R.A. 2015, Last glacial dynamics of the Vale of York and North Sea lobes of the British and Irish Ice Sheet. Proceedings of the Geologists' Association, 126(6): 712-730. doi:10.1016/j.pgeola.2015.09.005

Friend, R.J. 2011, The Last Glacial Maximum in the Vale of York. M.Sc. thesis at the School of Geosciences, Edinburgh University, Edinburgh, 234 p.

Friend, R.J., Buckland, P.C., Bateman, M.D. \& Panagiotakopulu, E. 2016, The 'Lindholme Advance' and the extent of the Last Glacial Maximum in the Vale of York. Mercian Geologist, 19(1): 18-25. URL: http://eprints.whiterose.ac.uk/109464/

Garton, D., Baker, C., Banks, V., Barton, N., Budge, D., Collcutt, S., Price, S., Ross, I., Tapete, D. \& Tyndall, R. 2015, Ice Age Journeys: Research by a Community Archaeology Group at Farndon Fields, Newark, Nottinghamshire. Transactions of the Thoroton Society of Nottinghamshire, 119: 103-139.

Grassam, A. \& Weston, P. 2015, Palaeolithic and Mesolithic South Yorkshire: Not Simply Dots on a Map. Yorkshire Archaeological Journal, 87(1): 3-10. doi:10.1179/0084427615Z.00000000047 
Harding, P., Ellis, C., Grant, M.J., Bates, M.R., Crowther, J., R.I., M. \& Schwenninger, J.-L. 2014, Late Upper Palaeolithic Fardon Fields. In: A46 Nottinghamshire. The archaeology of the Newark to Widmerpool Improvement Scheme, 2009 (Cooke, N. \& Mudd, A., Eds.), Cotswold Archaeology Monograph Vol. 7, Wessex Archaeology Monograph Vol. 34, Wessex Archaeology, Cirencester: p. 12-70. 